\title{
Examining the efficacy of DVD technology compared to print-based material in COPD self-management education of rural patients
}

\author{
Michael Stellefson ${ }^{1}$, Beth H. Chaney ${ }^{2}$, and J. Don Chaney ${ }^{2}$ \\ Coastal Carolina University ${ }^{1}$ and University of Florida ${ }^{2}$
}

\begin{abstract}
A pilot study $(n=41)$ was conducted to test the effects of three educational treatments (DVD vs. Pamphlet vs. DVD + Pamphlet) on health-related quality of life (HRQoL), COPD information needs and self-efficacy among a referred sample of Certified Federal Rural Health Clinic patients (mean age $=61.51$ years \pm 6.29 years; $\sim 61 \%$ female) suffering from COPD using a randomly-assigned, multiple-group pretest-posttest design with a control group. A MANCOVA testing planned multivariate contrasts determined patients receiving a DVD reported statistically significant higher levels of lung-specific physical functioning as compared to patients receiving a Pamphlet. Additionally, DVD patients reported clinically significant improvements on two dimensions of lung-specific HRQoL. No such improvements occurred within the Pamphlet and Control groups. The provision of self-management education as compared to usual care, however, did not improve the outcome variables examined.
\end{abstract}

(c) 2009 Californian Journal of Health Promotion. All rights reserved.

Keywords: COPD; self-management education; educational technology; rural; planned multivariate contrasts

\section{Introduction}

Chronic obstructive pulmonary disease (COPD) is a preventable and treatable disease, characterized by progressive airflow limitation that is not fully reversible and is associated with an abnormal inflammatory response of the lung to noxious particles or gases (Rabe, Hurd, \& Anzueto, 2007). The chronic airflow limitation characteristic of COPD is caused by a unique mixture of small airway disease (chronic bronchitis) and parenchyma destruction (emphysema), the relative contributions of which differ from person to person (Buist et al., 2007). Shortness of breath exacerbations are hallmark symptoms of COPD, causing a majority of disability and morbidity associated with the disease. COPD prevalence, morbidity and mortality are generally directly related to the prevalence of tobacco smoking and increased age, both of which contribute to diminished lung function. Among those already diagnosed with COPD, disease symptoms persist even if smoking cessation is realized (DomagalaKulawik, Maskey-Warzechowska, Kraszewska, \& Chazan, 2003). Moreover, if every smoker in the world were to stop smoking in the immediate future, rates of COPD incidence and prevalence would most likely continue to rise for the next 20 years (Kojima et al., 2007; Lopez et al., 2006). COPD is the fourth leading cause of death in the United States and is the only major cause of death in America for which no significant decreases in morbidity or mortality have been observed in the past 20 years (Norwood, 2006). Table 1 describes the adult prevalence and mortality rates of COPD based on race and gender in the U.S. Taking into account the expected aging of the U.S. population over the next 20 years and the past/current epidemic of smoking in America, it is highly unlikely that there will be any decline in the number of Americans with COPD in the near future (Mannino \& Buist, 2007; Jemal et al., 2005). 
Table 1. Current adult prevalence and mortality rates of COPD

\begin{tabular}{|c|c|c|c|c|c|c|c|c|c|c|}
\hline & \multicolumn{2}{|c|}{ Total } & \multicolumn{2}{|c|}{$\begin{array}{l}\text { Non-Hispanic } \\
\text { White }\end{array}$} & \multicolumn{2}{|c|}{$\begin{array}{l}\text { Non-Hispanic } \\
\text { Black }\end{array}$} & \multicolumn{2}{|c|}{ Hispanic } & \multicolumn{2}{|c|}{ Non-Hispanic } \\
\hline & Number & Rate & Number & Rate & Number & Rate & Number & Rate & Number & Rate \\
\hline Males & 59,221 & 51.2 & 52,762 & 54.5 & 3,763 & 42.1 & 1,566 & 26.0 & 57,492 & 52.5 \\
\hline Females & 63,062 & 36.2 & 58,190 & 40.5 & 2,850 & 18.9 & 1,309 & 14.4 & 61,618 & 37.5 \\
\hline Totals & 122,283 & 41.9 & 110,952 & 45.9 & 6,613 & 27.3 & 2,875 & 18.9 & 119,110 & 43.3 \\
\hline
\end{tabular}

Sources: National Center for Health Statistics, 2006; American Lung Association, 2007

Notes: (1) Rates are per 100,000 population and age-adjusted mortality rates are per 100,000 population.

(2) Hispanics are not mutually exclusive from Whites, African Americans, Asians/Pacific Islanders and American Indians/Alaska

\section{Personal Care Burden}

Pulmonary rehabilitation is a structured (usually hospital run) program of supervised and monitored physical activity, breathing therapy, behavioral management and modification (e.g., smoking cessation), and disease education that has been shown to improve quality of care for COPD patients (Rabe et al., 2007). The first enrollment in pulmonary rehabilitation is normally covered by Medicare for patients who qualify; however, patients who wish to continue rehabilitation after the first round of therapy must usually pay for it out of pocket. This type of maintenance program can prove to be quite costly for and not accessible to underserved, rural COPD patients. Given the ecological factors impacting patient education delivery between the provider and patient within a rural health clinic setting, practical self-management programs have been suggested to improve the overall management of COPD. COPD selfmanagement refers to: engaging in activities that promote adequate inhalation technique, building physiologic reserves, and preventing adverse health outcomes; monitoring respiratory and emotional status and making appropriate management decisions on the basis of this selfmonitoring; and managing the effects of illness on coping skills (Von Korff et al., 1997). The absence of third-party reimbursement to support these programs, however, makes teaching and learning between provider and patient quite difficult, especially in a rural health clinic environment. This is problematic, because patients report not having their disease-related concerns addressed during routine consultations (Tate et al., 1999).

\section{Dissatisfaction with Education Provided}

Older adults suffering from COPD have unique preferences for the manner in which they obtain self-management education (Carlson et al., 2006; Van Wynen, 2001). COPD patients report widespread dissatisfaction with the education they are provided (Barr et al., 2005; Gore, Brophy, \& Greenstoe, 2000; Jones, Hyland, Hanney, \& Erwin, 2004). In order to adequately self-manage COPD, patients must not only be educated in appropriate COPD self-management skills, but they must also confident that they can employ the knowledge and skills provided. The limited information patients receive during short interactions with their primary care physician, however, does not correspond with their learning needs for COPD self-management (Elkington \& White, 2002; Suhonen, Nenonen, Laukka, \& Valimaki, 2005). Because of this, some COPD patients do not feel connected to their health care providers. This feeling of disconnect affects patients' decision making regarding disease management (Leidy \& Haase, 1996).

\section{Effectiveness of COPD Self-Management Education}

In recent systematic reviews of the efficacy of COPD self-management education programs, an association was established between selfmanagement education and improved health- 
related quality of life (HRQoL), with no indication of detrimental effects on other related health outcomes (Effing et al., 2007). The improvement was regarded as too small, however, to reach clinical significance. Additionally, self-management education was found to have no effect on actual lung function. Given that the modification of declining lung function in patients with COPD is very difficult (even with long-term pharmacotherapy) (Yang et al., 2007), this should come as no surprise. Health educators have been encouraged to develop accessible interventions which assess and define effective COPD self-management education elements, "as data are still insufficient to formulate clear recommendations regarding the form and contents of self-management educational programmes in COPD" (Effing et al., 2007, p. 2). Moreover, "future studies [on COPD self-management [education]...should focus on the definition of effective elements of self-management [education] programs" (Effing et al., 2007, p. 9).

\section{Technology to Fill Research Gaps}

Interventions designed to provide mastery experiences for COPD self-management can increase a patient's efficacy beliefs for accomplishing self-management behaviors (Tsang, 2000). It has been suggested that older COPD patients appreciate and learn well from home-based educational programs which use audiovisual media to transmit targeted selfmanagement instruction (Constantinidou \& Baker, 2002; Finklestein \& Ratner, 2006; Nguyen et al., 2003; Petty et al., 2006). Petty et al. (2006) conducted a study to compare the effects of customized videotape education versus a standard videotape and usual care on HRQoL and functional ability among three groups of patients with COPD. Over an eight week study period, participants receiving customized videotape education demonstrated a statistically significant improvement in regards to coping skills associated with COPD self-management.

\section{Purpose of Present Study}

In light of these promising findings, the aim of the present pilot study was to measure and specifically compare the effect of three COPD self-management education dissemination strategies (and a control strategy) on relative differences in generic and disease-specific HRQoL, COPD information needs and COPD self-management self-efficacy among a rural population of clinic patients, a largely neglected demographic group in the research literature (Effing et al., 2007). The four educational treatments were: (a) Targeted RVision ${ }^{\mathrm{TM}}$ DVD segments (RVision ${ }^{\mathrm{TM}}$ Corporation, 2007); (b) a pre-produced written Pamphlet, Breathing Better With a COPD Diagnosis (National Heart, Lung and Blood Institute (NHLBI), 2007b); (c) Targeted RVision ${ }^{\mathrm{TM}}$ DVD segments and Breathing Better With a COPD Diagnosis; and (d) usual care (control).

\section{Hypotheses}

Hypothesis \# 1: Patients exposed to targeted DVD segments will outperform patients exposed to the educational Pamphlet on outcome variables related to COPD Informational Needs, COPD Self-Management Self-Efficacy, and HRQoL (Constantinidou \& Baker, 2002; Finklestein \& Ratner, 2006; Nguyen et al., 2003; Petty et al., 2006).

Hypothesis \# 2: Patients exposed to the targeted DVD and educational Pamphlet concurrently will underperform as compared to patients exposed to the DVD and educational Pamphlet alone, on outcome variables related to COPD Informational Needs, COPD Self-Management Self-Efficacy, and HRQoL (Consumer Information Processing Theory (CIPT), Rudd \& Glanz, 1990).

Hypothesis \# 3: Patients exposed to targeted DVD segments, educational Pamphlets, and both DVD segments and educational Pamphlets concurrently will outperform patients exposed to the usual care (control) condition on outcome variables related to COPD Informational Needs, COPD Self-Management Self-Efficacy, and HRQoL (Self-efficacy Theory, Bandura, 1997; Effing et al., 2007).

\section{Methods}

\section{Setting}

COPD patients were recruited from a Certified Federal Rural Health Clinic in a low 
socioeconomic status, rural Alabama County. In 2003 , it was reported that almost $20 \%$ of this population lived below the poverty line (National Association of Counties, 2004). This particular municipality was quite diverse, with $43.9 \%$ of its citizens being of African-American decent, and $52.8 \%$ being female. Further, this region of rural Alabama was designated as a Health Professional Shortage Area by the Federal Office of Health Professions (Alabama Medical Education Consortium, 2006).

\section{Sample}

A quota sample of 101 patients was contacted to participate in this pilot study, because these COPD clinic patients expressed written consent to participate and met specific inclusion criteria. The inclusion criteria were: (a) adults 50 years of age or older; (b) clinical diagnosis of COPD; (c) presence of dyspnea; (d) no formal COPD self-management education exposure within the last 6 months; (e) access to a DVD player; and (e) provision of informed consent. Institutional Review Board (IRB) approval was secured from a human subjects review committee for all protocol in this pilot study. The exclusion criteria consisted of: (a) housemate who previously agreed to participate in study and (b) being incapacitated to the point where COPD self-management was not feasible.

\section{Procedures}

For patient recruitment purposes, an incentive program was initiated to encourage clinic staff to recruit and retain study participants. Clinic staff members were asked to make telephone contacts with potential participants to tell patients (a) how the study would be carried out and (b) what the terms of participation were. The principal investigator provided telephone scripts for staff members to use when making these telephone calls, and the staff was collectively remunerated based on how many phone calls were made (i.e., $\$ 5$ per call). Selected patients were sent, via postal mail, a detailed study description approved by a human subjects committee, an informed consent document, and pretest instruments. The pretest instruments included adapted versions of the: (a) Lung Information Needs Questionnaire (Hyland, Jones, and Hanney, 2006); (b) Seattle Obstructive Lung
Disease Questionnaire (SOLQ) (Tu et al., 1997); (c) EuroQol-5 Dimension Scale (EQ-5D) and EuroQoL-Visual Analog Scale (EQ-VAS) (EuroQoL, 1990); and (d) the Self-efficacy for Managing Chronic Disease 6-Item Scale (SEMCD-6) (Lorig et al., 2001). The completion of these surveys was expected to take participants approximately 20 minutes to complete based on average reported survey completion times for each unique instrument. Each participant was offered a $\$ 40$ honorarium for participation in the study and was asked to review, sign and complete each form and survey and return the materials to the principal investigator via regular mail in a pre-paid postage envelope provided to them.

From the original 101 patients meeting the abovementioned inclusion criteria, 56 successfully completed the informed consent documentation and pretests, thus were assigned to different treatment groups.

Participants were randomly assigned into one of four groups. Group 1 participants (DVD group) were provided with a targeted RVision ${ }^{\mathrm{TM}}$ DVD (RVision Corporation, 2007) to view at home. Group 2 participants (Pamphlet group) were provided with a previously published Pamphlet entitled, Breathing Better With a COPD Diagnosis (NHLBI, 2007) to read at home. Group 3 participants (DVD + Pamphlet group) were provided with a targeted RVision ${ }^{\mathrm{TM}}$ DVD and the educational Pamphlet to read at home Each of the three group members were sent educational materials via regular mail and asked to review over the educational materials as often as possible over the two month treatment time period. Group 4 participants (Control group) did not receive any educational intervention and served as a usual care control group attending regularly scheduled doctor visits with no educational intervention. Figure 1 presents a graphical depiction of the research design. This particular research design reduced selection bias and increased analytical efficiency by randomly assigning participants into distinct treatment groups (Huberty \& Olejnik, 2006). 
Figure 1. Multiple-group pretest-posttest study design
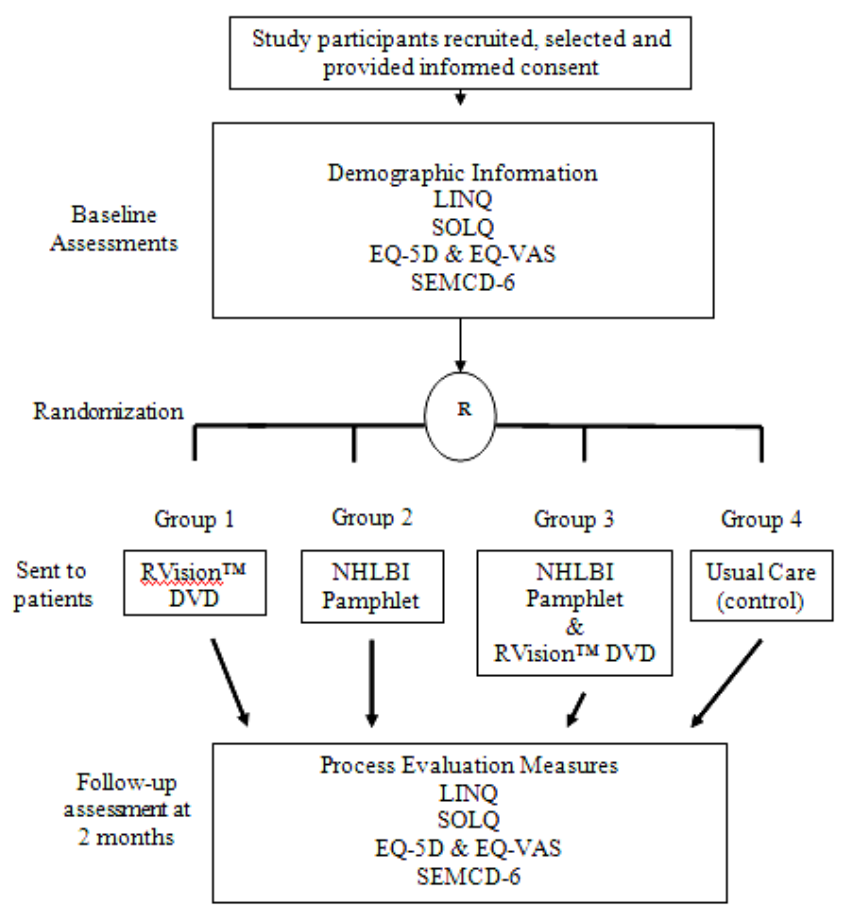

A multiple-group pretest-posttest design with pre- and post-tests. Group 1 was provided with the edited RVision ${ }^{\mathrm{TM}}$ DVD clips. Group 2 was provided with the NHLBI Pamphlet. Group 3 received both educational materials concurrently. Group 4 did not receive any educational materials.

After 1 month elapsed during the treatment time period, clinic staff contacted participants by phone to assess progress and remind patients to (a) review the educational material and (b) a second survey would be mailed to them in the near future. Clinic staff members were remunerated for making these status and reminder calls as well. Approximately one week before completion of the two month duration, each participant was mailed a series of follow-up surveys, which were identical to the surveys completed at baseline with the addition of process evaluation measures (for experimental groups) which assessed participants' perception of educational material(s) utility and also frequency of instructional resource use. After completion, participants mailed back the surveys in an envelope with pre-paid postage already attached. As was the case during the pretest time period, for every completed survey that was ultimately received by the principal investigator, clinic staff members were compensated a set amount of money per returned posttest. Following receipt of all posttests, all study participants were sent a debriefing document regarding the study, and clinic staff was sent all extra DVDs and Pamphlets to distribute to all clinic patients suffering from COPD.

\section{Treatment Content}

RVision Corporation ${ }^{\mathrm{TM}}$ (2007) developed a library of education content for home use for patients with COPD. Previous work has shown that patient use of this specific content can result in improvements of quality of life, fatigue and exercise compliance (Petty et al., 2006). Three COPD self-management educational segments cover almost 70 instructional topics including: pursed lip and diaphragmatic breathing techniques, infection management/treatment, medication management, smoking cessation, and energy conservation.

Table 2. Segments included on DVD

\begin{tabular}{|c|c|}
\hline Content & Running Time \\
\hline Introduction & $49 \mathrm{sec}$ \\
\hline Pursed Lip Breathing & $55 \mathrm{sec}$ \\
\hline Diaphragmatic Breathing & $1 \mathrm{~min}, 2 \mathrm{sec}$ \\
\hline Energy Conservation & $1 \mathrm{~min}, 34 \mathrm{sec}$ \\
\hline Introduction to Relaxation Techniques & $35 \mathrm{sec}$ \\
\hline Deep Breathing & $22 \mathrm{sec}$ \\
\hline Total Muscle Relaxation & $1 \mathrm{~min}, 39 \mathrm{sec}$ \\
\hline Visual Imagery & $21 \mathrm{sec}$ \\
\hline Helpful Hints for Relaxation & $24 \mathrm{sec}$ \\
\hline Avoiding Stress & $23 \mathrm{sec}$ \\
\hline Panic Control Breathing & $47 \mathrm{sec}$ \\
\hline Aerobics and Conditioning Introduction & $23 \mathrm{sec}$ \\
\hline Walking for Exercise & $2 \mathrm{~min}, 37 \mathrm{sec}$ \\
\hline Lifting and Breathing & $15 \mathrm{sec}$ \\
\hline Bending and Breathing & $24 \mathrm{sec}$ \\
\hline Infection Control & $1 \mathrm{~min}, 41 \mathrm{sec}$ \\
\hline Infection Detection & $1 \mathrm{~min}, 1 \mathrm{sec}$ \\
\hline Infection Treatment & $59 \mathrm{sec}$ \\
\hline When to Call Doctor & $1 \mathrm{~min} 17 \mathrm{sec}$ \\
\hline Controlling your Cough & $47 \mathrm{sec}$ \\
\hline Nutrition & $2 \mathrm{~min}, 39 \mathrm{sec}$ \\
\hline Increasing Your Fluid Intake & $1 \mathrm{~min}, 29 \mathrm{sec}$ \\
\hline House Keeping & $1 \mathrm{~min}, 11 \mathrm{sec}$ \\
\hline Smoking Cessation & $1 \mathrm{~min}, 22 \mathrm{sec}$ \\
\hline Conclusion & $22 \mathrm{sec}$ \\
\hline Total (approximate) & $34 \mathrm{~min}, 18 \mathrm{sec}$ \\
\hline
\end{tabular}


These segments ran for approximately 1 hour, and 30 minutes in length in total. To condense these DVD segments and target them to the learning needs of the participants in this study (Stellefson, 2008), video editing technology was used to compress the relevant patient education topics into one interval of approximately 30 minutes. These pertinent segments were loaded onto chapters within a reformatted DVD, so that patients could readily access segments of interest, without having to view the entire DVD at each sitting. Within each segment, sources of efficacy information included performance mastery techniques, role modeling, physiological coping, and verbal persuasion (Bandura, 1997). Table 2 lists the segments included on the reformatted DVD. The content within the Pamphlet included: facts about COPD, information about the pathology of COPD, what to do following a diagnosis, specific action steps for a COPD patient, and advice for seeking medical attention.

\section{Measures}

Demographic information including age, gender, race/ethnicity, marital/relationship status, educational level, income and living arrangements were obtained. The LINQ consisted of 17 self-reported items that measure the information needs of patients with COPD (Hyland, Jones, and Hanney, 2006). For the purposes of the present investigation, the subscales of self-management and exercise were measured and summed. The minimum total score of this adapted scale was zero (low information needs), while the maximum total score was 20 (high information needs). The test scores derived from these subscales have fair measures of reliability ( $\alpha=0.66$ to 0.78 ) (Hyland, Jones, \& Hanney, 2006). The SOLQ consisted of 29 items measuring four health dimensions: physical function, emotional function, coping skills, and treatment satisfaction. Each domain score is transformed on a scale of zero (worst) to 100 (best). Internal consistency $(\alpha=0.79$ to 0.93$)$, test-retest reliability ( $\mathrm{r}=0.64$ to 0.87 ), construct validity, and responsiveness have been very good when data was collected using all four subscales (Belza et al., 2005; Tu et al., 1997). The meaningful clinically significant difference in the score of the physical function domain has been estimated to be five points (Fan et al., 2002). The coping skills subscale is highly correlated $(r=0.93)$ with another commonly used measure of self-efficacy in COPD patients (cf. Tu et al., 1997; Wigal et al., 1991). The SOLQ is self-administered, written on a fourth grade level, and can be completed in five to ten minutes.

The EQ-5D (EuroQol Group, 1990) assesses (a) mobility, (b) self-care, (c) usual activity, (d) pain, and (e) anxiety/depression. For each domain, participants are asked to choose from three response option boxes ranging from no problems (level 1) to some problems (level 2) to inability or extreme difficulty (level 3). Each unique health state has an associated 5-digit descriptor ranging from 11111 for perfect health to 33333 for worst possible health $(35=243$ possible health states). Weights are used to score the responses to the five domains, with scores ranging from zero to one (where a score of one represents a perfect state) and then converted to a single index value using a value set derived through a Time Trade Off (TTO) valuation study (Shaw, Johnson, \& Coons, 2005). The EQ-5D valuation measurements have shown good testretest reliability (EuroQol Group, 1990) and generalizability (Van Agt, Essink-Bot, Krabbe, \& Bonsel, 1994). In addition, the visual analog scale (EQ-VAS) allows patients to rate their current health status from zero (worst imaginable health) to 100 (best imaginable health) by drawing a line through a thermometer like measure that indicates where each patient falls along a continuum that describes their current health status (EuroQol Group, 1990). EQ-VAS test scores have been reported to be reliable and responsive to measuring change in perceived health (Hurst et al., 1997). The SEMCD-6 (Lorig et al., 2001) is a six item scale that measures participants' self-efficacy to manage chronic disease. The score for the scale is the mean of the six items. Within this scale, patients are asked to rate their ability to control symptoms, physically and emotionally function, and communicate with their physician. The scales for these items range from one (not at all confident) to ten (totally confident). The reliability of test scores obtained from this 
measure have been high $(\alpha=0.91)$ (Lorig et al., 2001), and test-retest reliability of test scores derived from SEMCD-6 items were adequate ( $\mathrm{r}$ $=0.87$ ) (Lorig et al., 1996).

\section{Data Analysis}

A multivariate analysis of covariance (MANCOVA) was used to determine the effect of the three instructional strategies on the outcome variables of interest. Pretest scores were used as covariates to adjust for initial differences in the outcome variables. Cronbach's $\alpha$ reliability coefficients were examined to determine the appropriate pretest measure to use as covariate within the MANCOVA model. Three separate non-trend orthogonal planned contrasts (one pair wise and two complex) were tested. These contrasts specifically compared:

1. The outcome variable mean vectors for individuals in the DVD group, compared to the outcome variable mean vectors for individuals in the Pamphlet group

2. The two average outcome variable mean vectors collapsed across individuals in the DVD and Pamphlet group, compared to the outcome variable mean vectors for individuals in the DVD + Pamphlet group; and

3. The three average outcome variable mean vectors collapsed across individuals in the DVD, Pamphlet, and DVD + Pamphlet groups, compared to the outcome variable mean vectors for individuals in the Control group

If there were statistically significant differences across the centroids of these contrasts and there was an adequate adjusted effect size ( $\eta 2$ adj), then the effect was examined by consulting the resulting eigenvalue arising from each contrast. The vector of adjusted mean differences across the groups included in the orthogonal planned contrasts were computed and listed according to each dependent variable under examination. Next, structure coefficients between each dependent variable and canonical variable were inspected to determine which difference in which outcome measure was most relevant to the makeup of the resultant latent functions. The group adjusted mean centroids were then determined for each group on each identified dependent measure in order to characterize the nature of the group differences on the outcome variables most represented within the latent functions. The primary and/or secondary system(s) of constructs were then identified to best characterize the underlying nature of the canonical variables for each contrast effect.

\section{Results}

As stated earlier, 56 pretests were completed by willing participants (Pretest Response Rate = 55.4\%; Participant Dropout Rate $=44.6 \%$ ). Of the 56 participants completing the pretest surveys, 41 completed and returned all posttest surveys (Posttest Response Rate $=73.2 \%$; Participant Dropout Rate $=26.8 \%$ ). The mean age of participants was 61.51 years $(\mathrm{SD}=6.29$ years).

Table 3. Multiple group, pretest-posttest demographic characteristics

\begin{tabular}{|c|c|}
\hline "Characteristics & $n=41$ \\
\hline Age (mean \pm SD) & $\begin{array}{l}61.51 \text { years } \\
\pm 6.29 \text { years }\end{array}$ \\
\hline $\begin{array}{l}\text { Gender } \\
\text { Male } \\
\text { Female }\end{array}$ & $\begin{array}{l}16 \\
25\end{array}$ \\
\hline $\begin{array}{l}\text { Race } \\
\text { Caucasian (White) } \\
\text { African American (Black) }\end{array}$ & $\begin{array}{l}29 \\
12\end{array}$ \\
\hline $\begin{array}{l}\text { Educational level } \\
\text { Grade school } \\
\text { Some high school } \\
\text { High school graduate } \\
\text { Some college } \\
\text { College graduate } \\
\text { Graduate degree }\end{array}$ & $\begin{array}{c}9 \\
13 \\
11 \\
3 \\
3 \\
2\end{array}$ \\
\hline $\begin{array}{l}\text { Income } \\
\text { Less than } \$ 14,999 \\
\$ 15,000-\$ 24,999 \\
\$ 25,000-\$ 34,999 \\
\$ 35,000-\$ 49,999 \\
\$ 50,000-\$ 74,999 \\
\$ 75,000-\$ 99,999 \\
\$ 100,000+\end{array}$ & $\begin{array}{l}29 \\
8 \\
2 \\
2 \\
0 \\
0 \\
0\end{array}$ \\
\hline $\begin{array}{l}\text { Marital Status } \\
\text { Married } \\
\text { Widowed } \\
\text { Single }\end{array}$ & $\begin{array}{l}30 \\
3 \\
8\end{array}$ \\
\hline
\end{tabular}


The majority of participants were Caucasian ( $\mathrm{n}$ $=29)$, yet more than half were female $(n=25)$, and almost one-third were African American (n $=12$ ). Most participants reported educational levels ranging from only grade school to graduating from high school (cumulative $\%=$ $80.4)$, and most participants were married $(\mathrm{n}=$ 30). The overwhelming majority of participants reported annual incomes of less than $\$ 14,999$ (70.7\%), which most likely was attributable to this sample (mean age $=61.51$ years, $\mathrm{SD}=6.29$ years) drawing incomes primarily from social security and/or pensions. Table 3 presents all demographic information collected.

\section{Process Evaluation}

Almost $90 \%$ of participants $(87.5 \%)$ assigned to the intervention groups $(n=28)$ reported that they received the intended educational materials via regular mail. Only the participants who correctly identified the educational intervention they actually received and reviewed were included in the data analysis to protect against Type III error (Schwartz \& Carpenter, 1999). Over the two month treatment time period, participants receiving only the DVD reported viewing the DVD a mean of 1.75 times $(\mathrm{SD}=$ 1.91 times), while participants receiving the Pamphlet reported reviewing over it a mean of 2.16 times ( $S D=2.76$ times). Participants receiving both the DVD and Pamphlet over the 2-month treatment time period reviewed these instructional materials a mean of 3.4 times (SD $=1.71$ times). The mean number of views over the two month period was not statistically significantly different across the treatment groups, $\mathrm{F}(2,27)=1.38, \mathrm{p}=.27, \eta 2=.09$.

Participants were also asked to rate on scales from one to ten how useful they felt the intervention materials were (one $=$ not at all useful; ten = extremely useful) and also how understandable they felt the educational materials were $($ one $=$ not comprehensible; ten $=$ extremely comprehensible). The mean utility scores from participants across all treatment groups was relatively high $(\mathrm{M}=7.61, \mathrm{SD}=2.36)$ as were the mean comprehensibility scores $(\mathrm{M}=$ 8.21 , SD $=2.18$ ). While the overall scores on both measures were high, their differences were not statistically significant across treatments: Utility - F $(2,25)=.526, \mathrm{p}=.60, \eta^{2}=.04$; and Comprehensibility - F $(2,25)=.119, \mathrm{p}=.89, \eta^{2}$ $=.01$.

\section{Pretest and Posttest Data}

Table 4 presents means, standard deviations, and reliability indices for all pretest data obtained from the sample of participants who completed both the pre and posttest instruments $(n=41)$. Missing data was accounted for using procedures published within the scoring guidelines for each instrument. For the pretest data, the mean across all reliability indexes $(\alpha)$

Table 4. Descriptive statistics for pretests

\begin{tabular}{|c|c|c|c|c|c|}
\hline $\begin{array}{l}\text { Pretest Outcome } \\
\text { Variables }\end{array}$ & DVD & Pamphlet & $\begin{array}{c}\text { DVD + } \\
\text { Pamphlet }\end{array}$ & Control & Group \\
\hline
\end{tabular}

\begin{tabular}{|c|c|c|c|c|c|c|c|}
\hline \multicolumn{8}{|l|}{ SOLQ } \\
\hline Physical (18) & $M$ & $17.83(14.43)$ & $36.84(22.63)$ & $29.66(12.89)$ & $35.67(14.24)$ & $30.16(17.49)$ & .94 \\
\hline Emotional (5) & $M$ & $35.56(24.32)$ & $46.67(22.44)$ & $53.03(28.96)$ & $54.44(13.74)$ & $47.69(23.63)$ & .72 \\
\hline Coping (4) & $M$ & $33.33(17.68)$ & $55.83(20.71)$ & $47.35(25.09)$ & $57.41(23.82)$ & $48.61(23.24)$ & .66 \\
\hline $\begin{array}{l}\text { Treatment } \\
\text { Satisfaction (2) }\end{array}$ & $M$ & $58.33(38.53)$ & $68.75(33.46)$ & $56.82(30.80)$ & $52.78(22.34)$ & $59.29(31.11)$ & .82 \\
\hline LINQ-TOTAL (4) & $M$ & $12.44(6.06)$ & $8(5.81)$ & $8(4.73)$ & $7.78(5.78)$ & $8.97(5.69)$ & .85 \\
\hline SEMCD-6 (6) & $M$ & $3.44(2.67)$ & $4.27(2.26)$ & $4.24(2.73)$ & $5.48(1.91)$ & $4.35(2.44)$ & .97 \\
\hline EQ-5D (5) & $M$ & $.54(.20)$ & $.92(.99)$ & $.59(.23)$ & $.62(.18)$ & $.68(.57)$ & .64 \\
\hline EQ-VAS (1) & $M$ & $33.44(19.99)$ & $45(16.1)$ & $47.45(17.32)$ & $58.44(10.17)$ & $46.07(17.83)$ & N/A \\
\hline$n=$ & & 9 & 12 & 11 & 9 & 41 & \\
\hline
\end{tabular}


was 0.83 ( $\mathrm{SD}=0.12$ ); thus, the reliability estimates from the pretest data was judged to be acceptable for all scales. Based on the preconceived notion that patient self-efficacy for managing COPD would be highly correlated with both HRQoL and lung information needs, and given that the correlations between the SEMCD-6 pretest and specified outcome variables were moderate to high (upon inspection of the Pearson $r$ correlation matrix between pretest and posttest variables), the SEMCD-6 pretest variable was selected as a covariate to statistically adjust for pretest differences which may have existed between treatment group members. This decision was further supported by the pretest reliability estimate of the SEMCD-6 $(\alpha=.97)$. There did not exist a statistically significant difference in SEMCD-6 pretest scores across the treatment groups, $\mathrm{F}(2,38)=1.12, \mathrm{p}=.35, \eta^{2} \mathrm{adj}=.01$, which indicated that the participants were relatively homogeneous with respect to feeling able to self-manage their shortness of breath. Further, as with the other pretest variables, the data obtained from the SEMCD-6 did not violate the normality assumption of MANCOVA: skewness statistic $=.27(\mathrm{SE}=.37)$ and kurtosis statistic $=-.62(\mathrm{SE}=.72)($ Tabachnick \& Fidell, 2000).

Table 5 presents all posttest data. For all posttests, the adjusted means (i.e., means which statistically took into account pretest differences among participants on the SEMCD-6) were computed. All of the reliability estimates were judged to be acceptable. The mean across all reliability indexes for the posttest data was .80 $(\mathrm{SD}=0.13)$.

Table 5. Descriptive statistics for posttests

\begin{tabular}{|c|c|c|c|c|c|c|}
\hline Posttest Outcome Variables & & DVD & Pamphlet & DVD + Pamphlet & Control & Group \\
\hline \multicolumn{7}{|l|}{ SOLQ } \\
\hline Physical (18) & $A M$ & 39.37 & 19.93 & 35.33 & 28.56 & 30.80 \\
\hline Emotional (5) & $A M$ & 48.04 & 34.68 & 52.48 & 49.70 & 46.23 \\
\hline Coping (4) & $A M$ & 43.40 & 37.09 & 59.92 & 57.95 & 49.59 \\
\hline Treatment Satisfaction (2) & $A M$ & 47.68 & 60.07 & 60.61 & 63.39 & 57.93 \\
\hline LINQ-TOTAL (4) & $A M$ & 7.79 & 7.25 & 9.91 & 6.42 & 7.84 \\
\hline SEMCD-6 (6) & $A M$ & 5.10 & 7.15 & 3.35 & 5.21 & 5.20 \\
\hline EQ-5D (5) & $A M$ & .53 & .43 & .78 & .46 & .55 \\
\hline EQ-VAS (1) & $A M$ & 45.20 & 67.15 & 63.93 & 56.77 & 58.26 \\
\hline
\end{tabular}

Note: $A M=$ adjusted mean centroids; ( ) following scales/subscales represents number of items included within each

\section{Data Assumptions}

A multivariate test of the regression slope vectors was conducted using the Wilks lambda test $(\lambda)$ to ensure that the regression slope of the posttest outcome variables on the pretest covariate, SEMCD-6 pretest, was relatively equivalent for all groups being compared. The test provided little evidence to indicate that the mean vectors differed, as $\Lambda=.42, \mathrm{~F}(24,76.01)$ $=1.10, \mathrm{P}=.36$. To statistically confirm that $\mathrm{a}$ 
relatively strong relationship existed between the SEMCD-6 pretest variable and each of the outcome variables, a test of the vector of regression slopes which related the outcome variables to the SEMCD-6 pretest variable was conducted. Results from this test indicated that there was a non-statistically significant relationship between the SEMCD-6 pretest variable and each of the outcome variables at the .02 alpha level, $\Lambda=.65, \mathrm{~F}(8,29)=1.88, \mathrm{P}=$ $.09, \eta^{2}=.35, \eta_{\text {adj }}^{2}=.19$. However, while this test did not produce a statistically significant result, it did reveal a notable effect size $\left(\eta^{2}\right.$ adj $\left.=.19\right)$ which signaled that a relationship did exist to some degree between the SEMCD-6 variable and the outcomes variables of interest, thereby helping to reduce the error variance in the model and increase statistical power.

\section{Hypothesis Testing}

For hypothesis one (contrast one), the observed differences in the adjusted mean vectors of the outcome variables were statistically significant among the DVD and Pamphlet groups on the outcome variable vectors tested, $\Lambda=.42, \mathrm{~F}(8$, $29)=4.97, p=.001, \eta^{2}$ adj $=.48$. The SEMCD-6 (Raw Discriminant Function Coefficient $($ RDFC $\left.)=-.61, \mathrm{r}_{\mathrm{s}}^{2}=.14\right)$, SOLQ-Physical Function (RDFC $=.03, \mathrm{r}^{2}{ }_{\mathrm{s}}=.13$ ), and EQ-VAS $\left(\mathrm{RDFC}=-.02, \mathrm{r}_{\mathrm{s}}^{2}=.10\right)$ outcome variables contributed most to the resultant function. While the RDFC of the physical functioning subscale of the SOLQ (i.e., .03) and the EQ-VAS (i.e., .02) seemingly indicates non-contribution to the latent function, it is important to recognize that function coefficients are influenced by correlations between the outcome variables. Therefore, it is important to primarily consult the structure coefficients for the outcome variables (Thompson \& Borello, 1985). The physical functioning subscale of the SOLQ and the EQ-VAS possessed similar $r^{2}{ }_{s}$ to that of the SEMCD-6 thus were considered when interpreting the makeup of the function. Table 6 presents the DVD and Pamphlet group adjusted mean centroids for the three primary outcome variables defining the function.
Table 6. Group adjusted mean centroids for DVD and Pamphlet groups

\begin{tabular}{lcc}
\hline \hline Outcome variable & DVD & Pamphlet \\
\hline \hline SOLQ- Physical & 39.37 & 19.93 \\
\hline EQ-VAS & 45.20 & 67.15 \\
\hline SEMCD-6 & 5.09 & 7.15 \\
\hline \hline
\end{tabular}

For hypothesis two (contrast two), the observed differences in the adjusted mean vectors of the outcome variables were statistically significant among participants exposed to both interventions concurrently (DVD + Pamphlet) versus participants exposed to either the DVD or Pamphlet exclusively, $\Lambda=.30, \mathrm{~F}(8,29)=8.35$, $\mathrm{p}<.001, \eta_{\text {adj }}^{2}=.63$. The SEMCD-6 $(\mathrm{RDFC}=-$ $\left..87, \mathrm{r}_{\mathrm{s}}^{2}=.23\right)$, EQ-5D (RDFC $\left.=.02, \mathrm{r}^{2}{ }_{\mathrm{s}}=.19\right)$, and SOLQ-Coping (RDFC $=.02, \mathrm{r}^{2}{ }_{\mathrm{s}}=.10$ ) outcome variables contributed most to the resultant function. Again, while the RDFC of the EQ-5D (i.e., .02) and coping subscale of the SOLQ (i.e., .02) was very low, the squared structure coefficients describing their relationships with the canonical variables are noteworthy. Given that the coping skills subscale is highly correlated $(r=0.93)$ with another commonly used measure of self-efficacy in COPD patients (cf. Tu et al., 1997; Wigal et al., 1991), these two outcome variables (SEMCD-6 and SOLQ-Coping) can be conceptually put together to define COPD selfmanagement self-efficacy as the construct that best describes the latent function which under lied the contrast effect. Since the SEMCD-6 performed better than the coping subscale of the SOLQ maximizing the differences between the two contrasting groups, all COPD selfmanagement self-efficacy data interpretations focused on SEMCD-6 scale results. The EQ-5D variable contributed substantially to the latent function underlying the contrast effect. Table 7 presents the DVD + Pamphlet and the average of the DVD and Pamphlet group adjusted mean centroids for the SEMCD-6 and EQ-5D. Table 8 summarizes the statistically significant results from both contrasts one and two. 
Table 7. Group adjusted mean centroids for DVD + Pamphlet and the average of the DVD and Pamphlet groups collapsed together

\begin{tabular}{ccc}
\hline \hline Outcome variable & DVD + Pamphlet & Average of DVD and Pamphlet groups \\
\hline \hline SEMCD-6 & 3.35 & 6.13 \\
EQ-5D & .78 & .48 \\
\hline \hline
\end{tabular}

Table 8. Statistically significant test results for contrast analyses 1 and 2

\begin{tabular}{|c|c|c|c|c|c|}
\hline Effect & $\mathbf{r}_{\mathrm{s}}^{2}$ & $\begin{array}{c}\begin{array}{c}\text { Std. } \\
\text { weight }\end{array} \\
\end{array}$ & Wilks's $\Lambda$ & $\boldsymbol{F}$ & $p \& \eta_{a d j}^{2}$ \\
\hline \multicolumn{6}{|l|}{ DVD vs. Pamphlet } \\
\hline SOLQ-Physical & .13 & .03 & \multirow[t]{8}{*}{.42} & \multirow[t]{8}{*}{4.97} & \multirow{8}{*}{$\begin{array}{c}p=.001 \\
\eta_{\text {adj }}^{2}=.48\end{array}$} \\
\hline SOLQ-Emotion & .05 & .04 & & & \\
\hline SOLQ-Coping & .01 & .02 & & & \\
\hline SOLQ-Satisfaction & .03 & -.03 & & & \\
\hline LINQ-TOTAL & .0001 & -.10 & & & \\
\hline SEMCD-6 & .14 & -.62 & & & \\
\hline EQ-VAS & 10 & -.02 & & & \\
\hline EQ-5D & .03 & .14 & & & \\
\hline \multicolumn{6}{|c|}{ DVD + Pamphlet vs. the average of DVD and Pamphlet groups together } \\
\hline SOLQ-Physical & .002 & .01 & \multirow[t]{8}{*}{.30} & \multirow[t]{8}{*}{8.35} & \multirow{8}{*}{$\begin{array}{c}p<.001, \\
\eta_{a d j}^{2}=.63\end{array}$} \\
\hline SOLQ-Emotion & .03 & .05 & & & \\
\hline SOLQ-Coping & .10 & .02 & & & \\
\hline SOLQ-Satisfaction & .01 & .008 & & & \\
\hline LINQ-TOTAL & .02 & .008 & & & \\
\hline SEMCD-6 & .23 & -.87 & & & \\
\hline EQ-VAS & .02 & .01 & & & \\
\hline EQ-5D & .19 & .02 & & & \\
\hline
\end{tabular}

For hypothesis three (contrast three), the observed differences in the adjusted mean vectors of the outcome variables were not statistically significant among participants exposed to the DVD, Pamphlet, and/or both interventions concurrently (DVD + Pamphlet) versus participants exposed to usual care (Control), $\Lambda=.730, \mathrm{~F}(8,29)=1.34, \mathrm{p}=.265$. Because no functions were statistically significant at the .02 alpha levels, the structure coefficients between each dependent variable and canonical variable were not examined.

\section{Discussion}

Most participants (almost 90\%) reported receiving and reviewing the self-management education material that was sent to them via regular mail. Thus, the distribution strategy for the intervention materials proved to be quite effective. It is important to be cognizant, however, of response bias which may have been present among a sample receiving remuneration for their active participation in a study. Nonetheless, it was encouraging to note that 
participants found the educational materials to be useful and relatively easy to understand. It is inconclusive, however, as to which treatment was actually most easily utilized among this unique group of rural COPD patients.

\section{Differences between DVD Group and Pamphlet Group}

With regard to the physical functioning dimension of lung-specific HRQoL, the data supported the hypothesis posed, yet the finding specific to generic HRQoL contradicted the a priori hypothesis. Of note is the improvement on the physical functioning subscale of the SOLQ for participants in the DVD group. DVD group participants reported clinically significant improvements in physical and emotional functioning (i.e., an improvement of five points, see Tu et al., 1997). The same could not be said for the Pamphlet and Control groups. Exposure to standard self-management education had previously been associated with improvements in physical functioning, but did not reach a level of clinical significance in all previous studies (Effing et al., 2007). Thus, the clinically significant improvement in physical and emotional functioning linked with exposure to the targeted self-management DVD represents an important finding. The present pilot study supports the idea that exposure to audio-visual based education, as opposed to text based education, can clinically impact physical and emotional functioning among COPD patients (Petty et al., 2006).

Findings also suggested that of the two types of self-management education interventions tested, text based self-management education may be more effective to enhance COPD selfmanagement self-efficacy in a population similar to the rural, underserved sample in this pilot study. Previous studies only investigated and found within-group improvements in selfefficacy among patients exposed to group selfmanagement education as opposed to usual care. The present research supported different between-group effects of different COPD selfmanagement educational strategies on COPD self-management self-efficacy. Moreover, this pilot study was the first to specifically identifying Pamphlet distribution alone as the most effective educational strategy to positively influence COPD self-management self-efficacy among COPD patients.

It is important to note, however, that the above finding cannot be said in regards to generic HRQoL (i.e., HRQoL not specifically associated with a disease), as the data from this pilot study did not support increased efficacy of the DVD as opposed to the Pamphlet in relation to this more general construct. Furthermore, this study suggests there are differential effects of educational treatment on both generic and disease-specific HRQoL among COPD patients. Generic measures of HRQoL have generally been reported as weak among COPD patients (Guyatt et al, 1999) and more likely to detect effects unrelated to COPD. Disease-specific instruments have generally been more responsive to change (Puhan et al., 2007). The more the content of an instrument deviates from the concept under examination, the greater the error introduced and the lesser the accuracy of inferences (Hajiro, Nishimura, Tsukino, Toru, \& Takateru, 1999). Thus, the positive effect of the DVD on disease-specific HRQoL (i.e., physical functioning dimension) may be the more important finding.

\section{Differences between DVD/Pamphlet Groups Combined and Separated}

To increase COPD self-management selfefficacy, the results of this pilot study suggested that providing this sample with either a DVD or Pamphlet alone was more effective than providing participants with both interventions concurrently. This finding regarding COPD selfmanagement self-efficacy was notable and supported the hypothesis stating that both treatments concurrently would be less effective than distributing only one of the two instructional materials. Further, this result concurs with CIPT (Rudd \& Glanz, 1990), which emphasizes that health consumers can process and use only a limited amount of information at one time (Bettman, 1979). In light of these results regarding the effects of COPD self-management on self-efficacy, perhaps providing patients with too much information in different formats caused an "information overload" for participants and did not allow 
participants to ascertain the information needed to enhance their efficacy beliefs. These findings suggest that a "less is more" phenomena may be present and supports a singular educational strategy to enhance self-efficacy among COPD patients, which has been studied in the literature (Tsang, 2000). Patients may respond better to consistent messages regarding COPD selfmanagement and efforts aimed at reducing the potential for contradiction and/or confusion emanating from conflicting self-management tutorials. As well, most educational interventions designed to enhance COPD self-management education should usually be supplemented by other interpersonal support and not simply by way of information dissemination. Various planned learning experiences should be considered during the educational planning process based on the health-related outcome of interest for the practitioner's priority population (i.e. increased self-management self-efficacy or enhanced HRQoL).

\section{Differences between Interventions Groups Combined and Usual Care}

Somewhat surprisingly, the provision of selfmanagement education material as opposed to usual care did not improve the outcome variables of interest among this sample of COPD patients. This finding contradicts the hypothesis that self-management education would be more effective than usual care in regards to affecting the outcomes variables tested during this study. Furthermore, this particular finding questions the efficacy of self-management education (as opposed to usual care) in helping patients enhance their self-efficacy for COPD selfmanagement, reduce their informational needs related to COPD, and improve their HRQoL. The final conclusion of note is that there were no statistically significant findings related to COPD information needs. These results suggest that self-management education has little effect on patients' self-reported need for information related to COPD self-management.

\section{Limitations}

There are potential confounding influences especially an insufficient sample size, which may have contributed to this lack of statistically significant findings for contrast effect three. For example, in this pilot study, the number of participants $(\mathrm{n}=41)$ was lacking despite deliberate efforts to recruit patients. A post-hoc power analysis was conducted using $\mathrm{G}^{*}$ POWER ${ }^{\mathrm{TM}}$ software (Erdfelder, Faul, \& Buchner, 1996) to determine the power that was available to detect statistically significant differences in the outcome variables given the relatively low number of participants in this study. The result of this post-hoc power analysis indicated that power to detect statistically significant findings in this pilot study was extremely low at .43. An increase of approximately 26 participants would have resulted in more sufficient power (i.e., .80) to detect statistically significant differences when examining contrast three effects. Studies with more participants can generate more statistical power to detect statistically significant differences in outcomes, and are very necessary (Rabe et al., 2007). More longitudinal applications of a modified form of this research design and protocol could greatly augment the current understanding of the effectiveness of COPD self-management education in rural, diverse areas by using available rural health networks.

The validity of the participants' self-reported self-management behaviors was another concern in this study. In this research, self-report could have biased the data through participants' intentional or unintentional misrepresentation of their behaviors. Another possible limitation was reactivity (i.e., an individual may reduce or alter their behaviors in reaction to the daily monitoring of self-management). Possible other threats to internal validity included: unintended contamination among individuals within different treatment groups, diffusion of educational treatments among participants in disparate treatment groups, and selection bias robust against randomization and statistical adjustment. It is important to note that the effects of baseline pretest covariates were taken into account to reduce these threats to internal validity; however, while steps were taken to avoid such threats, they were nevertheless present. Some of these limitations were guarded against by using a control group in the design. It 
is also important to note that patients with Stage I (mild) COPD are more likely to report high levels of HRQoL; thus, self-management may have little impact on the overall well-being of patients (i.e., given that there is little room for improvement). Researchers and practitioners should not be all that surprised when selfmanagement education interventions do not impact patients with Stage I COPD, as they may be experiencing very little disease-related disability (Boubeau, 2004; Worth \& Dhein, 2004). Given that disease stage data was not collected in this pilot study, it cannot be determined whether a stage effect may have impacted the results of this contrast analysis.

\section{Implications}

The evidence suggested that the DVD was a more effective intervention relative to the pamphlet intervention in helping rural patients function better physically with their disease as compared to patients provided with a Pamphlet. DVD patients reported clinically significant improvements on physical functioning dimensions of lung-specific HRQoL, while no such improvements occurred within the Pamphlet and Control groups. However, rural patients provided with a DVD did not report better generic HRQoL as compared to participants receiving a Pamphlet alone. When both educational interventions (DVD + Pamphlet) were provided to rural patients concurrently, there was a marked improvement in patients' generic HRQoL. In addition, rural patients provided with Pamphlets revealed greater improvements in COPD selfmanagement self-efficacy than did patients who only received the DVD. Finally, providing rural patients with any type or combination of COPD self-management education showed no statistically significant improvements on the outcome variables considered together as compared to patients provided with usual care. In sum, the results from this pilot study suggest that COPD self-management DVDs can be effective in helping rural patients experience better physical functioning (a lung-specific HRQoL measure), and, in conjunction with textbased Pamphlets, can improve generic HRQoL in rural COPD patients more so than exposure to text-based Pamphlets alone. Practitioners should use caution, however, when attempting to generalize findings from this pilot study to other rural populations, given the limited sample size.

\section{Acknowledgements}

This project is supported by grant number R36HS017387 from the Agency for Healthcare Research and Quality (NIH). The content is solely the responsibility of the author and does not necessarily represent the official views of the Agency for Healthcare Research and Quality. Also, special thanks goes to Charles P. Spickert, $\mathrm{MPH}$, President and CEO of RVision ${ }^{\mathrm{TM}}$ Corporation; Dr. Katherine Hensleigh, MD; Ms. Wendy Ridgeway, CNA; Danny Ballard, Ed.D.; James Eddy, D.Ed.; and Rafael Lara-Alecio, Ph.D. for their support of this research.

\section{References}

American Lung Association. (2007b). State of lung disease in diverse communities: 2007. Retrieved on October 22, 2007, from http://www.lungusa.org/site/pp.asp?c=dvLUK9O0E\&b=308853.

Alabama Medical Education Consortium, The. The status of primary healthcare in Choctaw County, August 2006. Retrieved November 13, 2007, from http://www.amec.uwa.edu/PDFFiles/ CoPCStudies/CHOCTAW2006revised.pdf.

Bandura, A. (1997). Self-efficacy: The exercise of control. New York: W.H. Freeman and Company.

Barr, R. G., Celli, B., \& Martinez, F., Ries, A., Rennard, S., Reilly, Jr., J., et al. (2005). Physician and patient perceptions in COPD: The COPD resource network needs assessment survey. American Journal of Medicine, 118, 1415.

Belza, B., Steele, B. G., Cain, K., Coppersmith, J., Howard, J., \& Lakshminarayan, S. (2005). Seattle obstructive lung disease questionnaire: Sensitivity to outcomes in pulmonary rehabilitation in severe pulmonary illness. Journal of Cardiopulmonary Rehabilitation, 25, 107-114. 
Bettman, J. R. (1979). An information processing theory of consumer choice. Reading, MA: AddisonWesley.

Bourbeau, J. (2004). Self-management interventions to improve outcomes in patients suffering from COPD. Expert Review of Pharmacoeconomics Outcomes Research, 4, 71-77.

Buist, A. S., McBurnie, M. A., Vollmer, W. M., Gillespie, S., Burney, P., Mannino, D. M., et al. (2007). International variation in the prevalence of COPD (The BOLD Study): A population-based prevalence study. Lancet, 370, 741-749.

Carlson, M. L., Ivnik, M. A., Dierkhising, R. A. O'Byrne, M. M., \& Vickers, K. S. (2006). A learning needs assessment of patients with COPD. Medical Surgery \& Nursing, 15, 204-212.

Constantinidou, F., \& Baker, S. (2002). Stimulus modality and verbal learning performance in normal aging. Brain and Language, 82, 296-311.

Domagala-Kulawik, J., Maskey-Warzechowska, M., Kraszewska, I., \& Chazan, R. (2003). The cellular composition and macrophage phenotype in induced sputum in smokers and ex-smokers with COPD. Chest, 123, 1054-1059.

Effing, T., Monninkhof, E. M., van der Valk, P. D. L. P. M., van der Palen, J., van Herwaarden, C. L. A., Partridge, M. R., et al. (2007). Self-management education for patients with chronic obstructive pulmonary disease (Review). Cochrane Database of Systematic Reviews 2007, 4, 1-398.

Elkington, H., \& White, P. (2002). Chronic obstructive pulmonary disease and primary care. British Journal of General Practice, 52, 532-534.

Erdfelder, E., Faul, F., \& Buchner, A. (1996). GPOWER: A general power analysis program. Behavior Research Methods, Instruments, \& Computers, 28, 1-11.

EuroQol Group. (1990). EuroQol-A new facility for the measurement of health-related quality of life. Health Policy, 16, 199-208.

Fan, V., Curtis, J. R., MacDowell, M., \& Fihn, S. D. (2002). Using quality of life to predict hospitalization and mortality in patients with obstructive lung diseases. Chest, 122, 429-436.

Finkelstein, S. M., \& Ratner, E. (2006). Managing chronic disease through home telehealth. Minnesota Medical Journal, 89, 42-45.

Gore, J. M., Brophy, C. J., \& Greenstoe, M. A. (2000). How well do we care for patients with end stage chronic obstructive pulmonary disease (COPD)? A comparison of palliative care and quality of life in COPD and lung cancer. Thorax, 55, 1000-1006.

Guyatt, G. H., King, D. R., Feeny, D. H., Stubbing, D., \& Goldstein, R. S. (1999). Generic and specific measurement of health-related quality of life in a clinical trial of respiratory rehabilitation. Journal of Clinical Epidemiology, 52, 187-192.

Hajiro, T., Nishimura, M., Tsukino, A. I., Toru, O, \& Takateru, I. (1999). A comparison of the level of dyspnea versus disease severity in indicating the health-related quality of life of patients with COPD. Chest, 116, 1632-1637.

Huberty, C. J, \& Olejnik, S. (2006). Applied MANOVA and discriminant analysis (2nd ed.). John Wiley \& Sons, Inc.: Hoboken, NJ.

Hyland, M. E., Jones, R. C., \& Hanney, K. (2005). The information needs of COPD patients: Why we developed the LINQ. The Airways Journal, 142-145.

Jemal, A., Ward, E., Hao, Y., \& Thun, M. (2005). Trends in the leading causes of death in the United States, 1970-2002. Journal of the American Medical Association, 294, 1255-1259.

Jones, R. C. M., Hyland, M. E., Hanney, K., \& Erwin, J. (2004). A qualitative study of compliance with medication and lifestyle modification in chronic obstructive pulmonary disease (COPD). Primary Care Respiratory Journal, 13, 149-154.

Kojima, S., Sakakibara, H., \& Motani, S. (2007). Incidence of chronic obstructive pulmonary disease, and the relationship between age and smoking in a Japanese population. Journal of Epidemiology, 17, 54-60.

Leidy, K., \& Haase, J. (1996). Functional performance in people with chronic obstructive pulmonary disease: A qualitative analysis. Advanced Nursing Science, 18, 77-89. 
Lopez, A. D., Mathers, C. D., Ezzati, M., Jamison, D. T., \& Murray, C. J. L. (2006). Global burden of disease and risk factors. Washington, DC: The World Bank.

Lorig, K., Stewart, A., Ritter, P., Gonzalez, V., Laurent, D., \& Lynch, J. (1996). Outcome measures for health education and other health care interventions. Thousand Oaks, CA: Sage Publications.

Lorig, K. R., Sobel, D. S., Ritter, P. L., Laurent, D., \& Hobbs, M. (2001). Effect of a self-management program for patients with chronic disease. Effective Clinical Practice, 4, 256-262.

Mannino, D. M., \& Buist, A. S. (2007). Global burden of COPD: Risk factors, prevalence, and future trends. Lancet, 370, 765-773.

National Association of Counties (2004). Rural counties in Alabama. Retrieved November 13, 2007, from http://quickfacts.census.gov/qfd/states/01/01023.html.

National Center for Health Statistics. (2006). National Health Interview Survey, 2004 [Computer file]. ICPSR04349-v2. Hyattsville, MD: U.S. Dept. of Health and Human Services, National Center for Health Statistics.

National Heart, Lung and Blood Institute. (2007). Breathing better with a COPD Diagnosis. Retrieved October 23, 2007, from http://www.nhlbi.nih.gov/health/public/lung/copd/campaignmaterials/html/copd-patient.htm.

Nguyen, H. G., Carrieri-Kohlman, V., Rankin, S. A., Slaughter, R., \& Stulberg, M. S. (2003). Pilot study of an online dyspnea self-management program for COPD. American Medical Informatics Association 2003 Symposium Proceedings, 951.

Norwood, R. (2006). Prevalence and impact of depression in chronic obstructive pulmonary disease patients. Current Opinion in Pulmonary Medicine, 12, 113-117.

Petty, T. L., Dempsey, E. C., Collins, T., Pluss, W., Lipkus, I., Cutter, G. R., et al. (2006). Impact of customized videotape education on quality of life in patients with chronic obstructive pulmonary disease. Journal of Cardiology Rehabilitation, 26, 112-117.

Puhan, M. A., Guyatt, G. H., \& Goldstein, R. (2007). Relative responsiveness of the Chronic Respiratory Questionnaire, St. Georges Respiratory Questionnaire and four other health-related quality of life instruments for patients with chronic lung disease. Respiratory Medicine, 101, 308-316.

Rabe, K. F., Hurd, S., \& Anzueto, A. (2007). Global strategy for the diagnosis, management, and prevention of chronic obstructive pulmonary disease: GOLD executive summary. American Journal of Respiratory and Critical Care Medicine, 176, 532-555.

RVision ${ }^{\mathrm{TM}}$ Corporation. (2007). COPD education. Distributed by HealthIx; Golden, CO. Retrieved on October 23, 2007, from http://www.healthix.com/SearchResults.asp?Cat=5.

Rudd, J., \& Glanz, K. (1990). How individuals use information for health action and consumer information processing. In Glanz K, Lewis F, Rimer B, (Eds.). Health behavior and health education: Theory, research and practice. San Francisco, CA: Jossey-Bass.

Schwartz, S., \& Carpenter, K. M. (1999). The right answer for the wrong question: Consequences of type III error for public health research. American Journal of Public Health, 89, 1175-1180.

Shaw, J. W., Johnson, J. A., \& Coons, S. J. (2005). US valuation of the EQ-5D health states: Development and testing of the D1 valuation model. Medical Care, 43, 203-220.

Stellefson, M. L. (2008). Conducting qualitative focus groups to assess the self-management experiences and learning needs of rural chronic obstructive pulmonary disease (COPD) patients. Manuscript submitted for publication.

Suhonen, R., Nenonen, H., Laukka, A., \& Valimaki, M. (2005). Patients' informational needs and information received do not correspond in hospital. Journal of Clinical Nursing, 14, 1167-1176.

Tabachnick, B. G., \& Fidell, L. S. (2001). Using multivariate statistics, 4th ed. Needham Heights, MA: Allyn \& Bacon.

Tate, P., Foulkes, J., Neighbour, R., Campion, P., \& Field, S. (1999). Assessing physicians' interpersonal skills via videotaped encounters: A new approach for the Royal College of General Practitioners Membership examination. Journal of Health Communication, 4, 143-152.

Thompson, B., \& Borello, G. M. (1985). The importance of structure coefficients in regression research. Educational and Psychological Measurement, 45, 203-209. 
Tsang, A. H. (2000). Effectiveness of three strengths of education and exercise on self-efficacy for walking and self-efficacy for managing dyspnea in patients with chronic obstructive pulmonary disease. (Doctoral dissertation, University of California San Francisco, 2000).

Tu, S. P., McConell, M. B., Spertus, J. A., Steele, B. G., \& Fihn, S. D.. (1997). A new self-administered questionnaire to monitor health-related quality of life in patients with COPD. Chest, 112, 614622.

Van Agt, H. M. E., Essink-Bot, M. L., Krabbe, P. F. M., \& Bonsel, G. J. (1994). Test-retest reliability of health state valuations collected with the EuroQol questionnaire. Social Science Medicine, 39, $1537-1544$.

van Wynen, E. A. (2001). A key to successful aging: Learning-style patterns of older adults. Journal of Geriatric Nursing, 27, 6-15.

Von Korff, M., Gruman, J., Schaefer, J., Curry, S. J., \& Wagner, E. H. (1997). Collaborative management of chronic illness. Annals of Internal Medicine, 127, 1097-1102.

Wigal, J. K., Creer, T. L., \& Kotses, H. (1991). The COPD self-efficacy scale. Chest, 99, 1193-1196.

Worth, H., \& Dhein, Y. (2004). Does patient education modify behaviour in the management of COPD? Patient Education and Counseling, 52, 267-270.

Yang, I. A., Fong, K. M., Sim, E. H. A., Black, P. N., \& Lasserson, T. J. (2007). Inhaled corticosteroids for stable chronic obstructive pulmonary disease. Cochrane Database of Systematic Reviews, 2(CD002991), DOI:10.1002/14651858.CD002991.pub2.

Author Information

*Michael Stellefson, Ph.D.

Assistant Professor

Coastal Carolina University

Department of Health Promotion

PO Box 261954

Conway, SC 29528

Email: mstel45@aol.com

Fax: (979)862-2672

Telephone: (717)645-3479

Beth H. Chaney, Ph.D., CHES

Assistant Professor

University of Florida

Department of Health Education and Behavior

J. Don Chaney, Ph.D., CHES

Assistant Professor and Assistant Dean

University of Florida

College of Health and Human Performance

Department of Health Education and Behavior

* corresponding author 